\title{
Studies on Aeromycoflora in Different Tea Estates of Sylhet
}

\author{
S. M. Abdullah ${ }^{1}$, Iftekhar Ahmad ${ }^{1 *}$, Mohammad Ohid Ullah ${ }^{2}$, Rayhan Uddin ${ }^{1}$, \\ W. U. Rahman ${ }^{1}$, R. Ara ${ }^{1}$, Yasin $M^{1}$
}

\author{
Department of Food Engineering and Tea Technology, Shahjalal University of Science and Technology, \\ Sylhet, Bangladesh ${ }^{1}$ \\ Department of Statistics, Shahjalal University of Science and Technology, Sylhet, Bangladesh ${ }^{2}$
}

\begin{abstract}
An attempt was made for the purpose of evaluation, isolation, and identification of the fungal load in air of Malnicherra \& Lakkhatura tea estates (from field to factory) in Sylhet Region during $15^{\text {th }}$ January to $15^{\text {th }}$ April 2017. The study was carried out in six different sections of the tea estates namely Nursery field, Matured field, Withering trough, Fermenting area, Drying zone, Sorting and Grading zone. The maximum microbial load was observed in Nursery field followed by Matured Tea Field, Sorting and Grading zone, Fermenting area, Withering trough and drying zone respectively. A total of 14 airborne fungal species were observed and among them, Aspergillus, Curvularia, Cladosporium, Penicillium, Rhizopus were the dominating genera in the air of tea estate. At Malnicherra tea estate Aspergillus fumigatus (12.39\%) showed the maximum percentage followed by Aspergillus flavus (19.88\%), Curvularia interseminata (19.74\%), Aspergillus niger (17.96\%) whereas Lakkatura tea estate Cladosporium herbarum (22.70\%) showed the maximum percentage followed by Curvularia interseminata (20.28\%), Aspergillus fumigatus (20.23\%), Rizopus nigricans (19.47\%). As fungal diseases are detrimental to the wellbeing of people, plant and animal health conditions, proper actions should be taken to protect tea estate workers and tea plants.
\end{abstract}

Keywords: Aeromycoflora, Microbial Load, Camellia Sinensis, Fungal Species, Health

\section{INTRODUCTION}

Aeromycoflora simply refers to the airborne fungal contributors of the environment and considered acting as an indicator of the level of atmospheric bio-pollution [1]. They are the important components environments and originate from soil, water, plants, and animal remains [2]. Their occurrence and proliferation in the air depend on geographical location, topography, meteorological factors, vegetation and human activity, processes involved in the production, wind, rainfall, temperature, and humidity [3-6].

The Airborne fungal spores possess a significant impact in human life due to their ability to spoil food and possessiveness of medical impact as to the cause of a variety of diseases [7-9]. They have been recognized to cause allergic problems including asthma, sore throat and sinus and eye irritation due to differential deposition in the respiratory system and most significantly more than $80 \%$ micro fungal genera have been associated with respiratory disorders [10-12]. In case of the agricultural plantation, through the air aeromycoflora disperse and deposit on the leaf surface, some on the ground and finally in the soil and cause many diseases in plants like wilts, leaf spots, etc. [13]. Most of the allergenic fungi are classified under Ascomycetes, Deuteromycetes, and Basidiomycetes \& some genera of airborne fungal spores such as Alternaria sp., Aspergillus sp., \& Cladosporium sp. are found throughout the world [14].

Tea (Camellia sinensis) is one of the most common drinks in the world and mostly grown in the high ambient tropical temperatures region. These growing conditions, as well as the chemical composition of tea, make tea plants and its ambiance a good medium for the growth of aeromycoflora [15].

Like others, tea has been extensively cultivated in Bangladesh since the $18^{\text {th }}$ century and from the previous studies, it is evident that the air of Bangladesh carries various mycoflora [16, 17]. But no systematic study has been carried out concerning aeromycoflora of tea gardens in Bangladesh, up to now. Therefore, the present study has been undertaken for evaluation of distribution pattern, isolation and identification of the fungal species at tea gardens and factories air in the Sylhet region of Bangladesh. 


\section{MATERIALS AND METHODS}

During the investigation, two tea estates i.e., Malnicherra and Lakkatura tea estate were selected. Observations were recorded at six different sections namely Nursery field, Matured field, Withering trough, Fermenting area, Drying zone and Sorting \& Grading zone of the selected two estates.

In this study, the culture plate method [18] was used for counting the fungal population in the air. Sterilized Petri plates of $9 \mathrm{~cm}$ diameter containing Potato Dextrose Agar (PDA) and Sabouraud Dextrose Agar (SDA) medium were used at fifteen days intervals for air sampling for a period of three months i.e., from $15^{\text {th }}$ January to $15^{\text {th }}$ April 2017. One Petri plate was used for each sampling zone in every interval. The plates were kept at 2- 3 feet above the ground in morning (between 9-10 am) and afternoon (between 4-5 pm) and exposed for 5 minutes for trapping of fungal flora on the basis of gravitational fall $[19,20]$. After that, the exposed Petri plates were sealed with paraffin strip and taken into the laboratory and incubated at room temperature $\left(25 \pm 2^{\circ} \mathrm{C}\right)$ for $48-72$ hours. The fungal colonies developed on the culture media were examined, counted and identified with the help of a compound microscope, microscopic slide and standard mycological books or manuals and available published literature [21].

The percentage contribution of aeromycoflora was calculated by the following formula [22, 23].

$\%$ Contribution $=($ Total number of colonies of one species $/$ Number of colonies of all species $) \times 100$

This systematic working procedure of the study can be shown as Fig. 1.

Agar medium preparation

$\checkmark$

Sterilization of medium in aseptic condition

$\checkmark$

Placing in petri dish in aseptic condition

$\checkmark$

Transportation of media into the Tea Estates (field and factory)

$\checkmark$

Exposure for 5-10 $\mathrm{min}$

$\checkmark$

Aseptically brought to the laboratory

$\downarrow$

Incubation for 2-3 days at room temperature

$\checkmark$

Fungal identification by available literature

Fig. 1. Working procedure followed in aeromycoflora study of different Tea Estate of Sylhet.

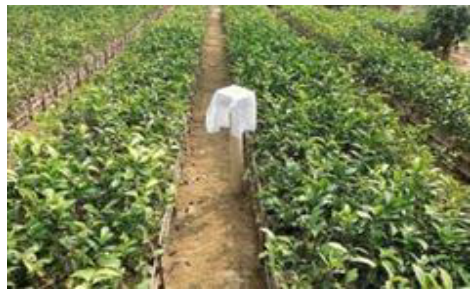

(a) Nursery field

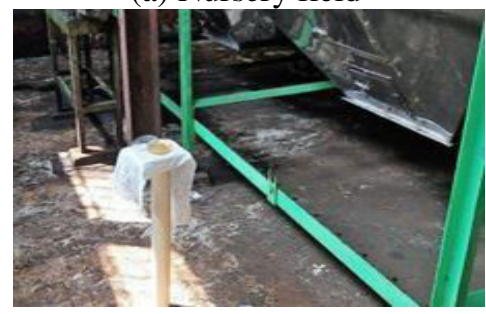

(d) Fermenting area

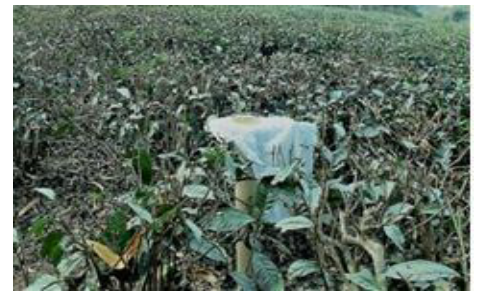

(b) Matured field

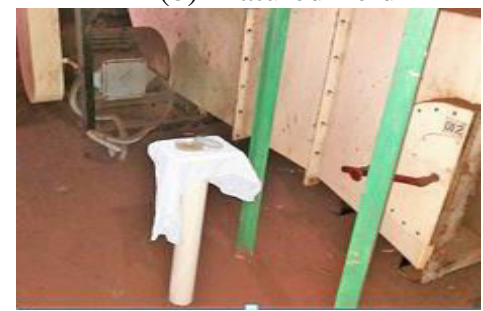

(e) Drying zone

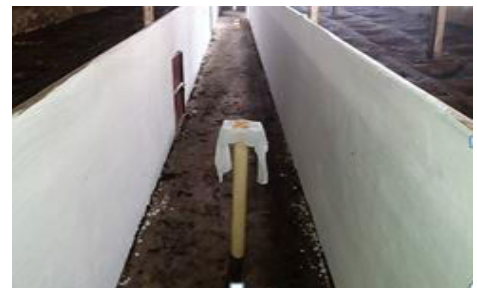

(c) Withering trough

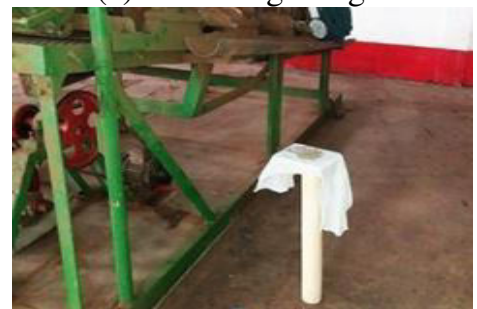

(f) Sorting and Grading zone 
Fig. 2. Sample collection from different selected sections (a-f) of tea estates

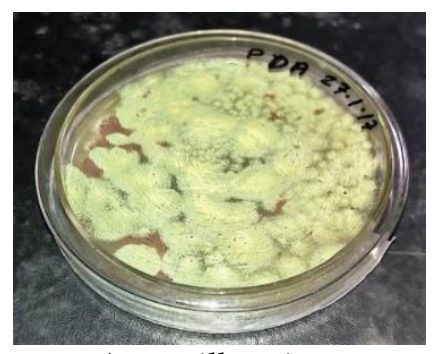

Aspergillus niger

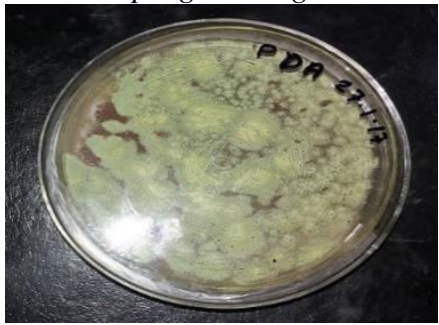

Curvularia interseminata

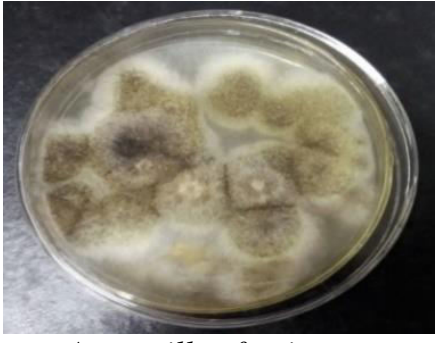

Aspergillus fumigatus

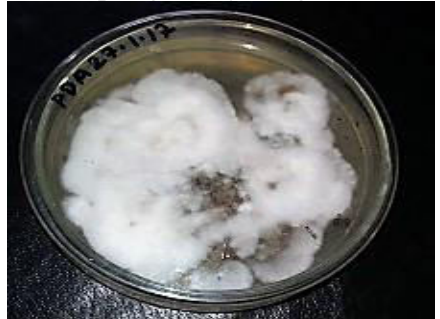

Penicillium spinulosum

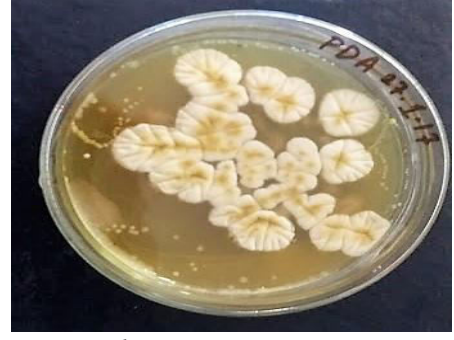

Rhizopus nigricans

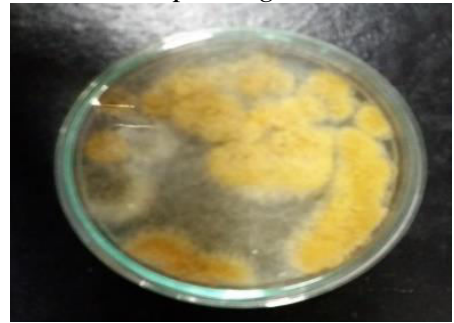

Cladosporium oxysporum

Fig. 3. Isolation of different types of aeromycoflora (a-f) from selected locations of Tea Estates

\subsection{STATISTICAL ANALYSIS}

The data analysis was undertaken with a SPSS program. Principle Component Analysis was done to detect the important species.

\section{RESULTS AND DISSCUSSION}

The culture plate exposure technique has proved to be more appropriate over others, and has been employed for the detection of aeromycoflora in the present study to record fungal diversity [23].

The results of the study showed that the air of tea gardens and factories was never free of fungal spores. During the three months of investigation, a total of 14 types of fungal spores were identified in different zones of Malnicherra and Lakkatura tea estate. Besides the fungal spores the other bioparticles i.e., miscellaneous types were also recorded. The colony forming unit (CFU) of each of the represented mycoflora was calculated to find out the level of contamination of different zones. Range of colony forming unit (CFU) were expressed as ( - ) indicates 0-30 CFU , ( + ) indicates 31-60 CFU , (++ ) indicates 61-90 CFU , (+++ ) indicates 91-120 CFU, ( ++++) indicates 121-150 CFU in (Table 1.). From the table it was explored that highest number of fungal species exist in Nursery field followed by Matured field, Sorting and Grading zone, Fermenting area, Withering trough and drying zone respectively. It was noticeable that there was a negligible amount of Microbial Load observed in the drying zone. The reason might the presence of heating source and High temperature at the drying step.

According to their occurrence in the exposed Petri plate samples in Malnichera tea a total of 2278 and 2406 colonies were identified in PDA and SDA media respectively. Among the colonies identified in PDA media maximum \% of contribution (Table 2.) showed by Aspergillus fumigatus (12.73\%) followed by Aspergillus flavus (10.53\%), Curvularia interseminata (9.56\%), Aspergillus niger (9.08\%), Cladosporium herbarum (8.16\%), Penicillium spinulosum (8.12\%), Rhizopus nigricans (7.46\%), Mycelia sterilia (6.71\%), Fusarium lactis (5.35\%), Penicillium sp. $(3.73 \%)$, Alternaria alternata $(3.2 \%)$, Cladosporium oxysporum $(3.02 \%)$, Nigrospora oryzae $(2.51 \%)$, Bispora sp. $(2.06 \%)$.

Table 1. Percentage of load of different fungal species at different locations (in field to factory)

at Malnicherra and Lakkatura Tea Estate

\begin{tabular}{|c|c|c|c|c|c|c|c|c|c|c|c|c|c|}
\hline \multirow[t]{2}{*}{$\begin{array}{l}\text { Sl. } \\
\text { No }\end{array}$} & \multirow[t]{2}{*}{$\begin{array}{c}\text { Name of The } \\
\text { Fungal Species }\end{array}$} & \multicolumn{2}{|c|}{$\begin{array}{c}\text { Nursery } \\
\text { field }\end{array}$} & \multicolumn{2}{|c|}{$\begin{array}{l}\text { Matured } \\
\text { field }\end{array}$} & \multicolumn{2}{|c|}{$\begin{array}{c}\text { Withering } \\
\text { trough }\end{array}$} & \multicolumn{2}{|c|}{$\begin{array}{c}\text { Fermentin } \\
\mathrm{g} \text { area }\end{array}$} & \multicolumn{2}{|c|}{$\begin{array}{c}\text { Drying } \\
\text { zone }\end{array}$} & \multicolumn{2}{|c|}{$\begin{array}{c}\text { Sorting \& } \\
\text { Grading zone }\end{array}$} \\
\hline & & G1 & G2 & G1 & $\mathrm{G} 2$ & G1 & $\mathrm{G} 2$ & G1 & G2 & G1 & $\mathrm{G} 2$ & G1 & $\mathrm{G} 2$ \\
\hline 1 & Alterinaria alternata & + & + & + & + & - & - & - & - & - & - & & + \\
\hline 2 & Aspergillus flavus & + & ++ & + & ++ & ++ & + & + & + & + & - & ++ & ++ \\
\hline 3 & Aspergillus fumigatus & ++++ & ++ & +++ & ++ & + & ++ & + & + & + & - & ++ & ++ \\
\hline 4 & Aspergillus niger & ++ & ++ & ++ & ++ & + & + & + & + & - & - & ++ & ++ \\
\hline
\end{tabular}


Vol. 6, Issue 12, December 2019

\begin{tabular}{|c|c|c|c|c|c|c|c|c|c|c|c|c|c|}
\hline 5 & Bispora sp. & - & + & - & + & - & - & - & - & - & - & ++ & - \\
\hline 6 & Cladosporium herbarum & ++ & ++ & ++ & ++ & + & ++ & ++ & ++ & - & - & + & ++ \\
\hline 7 & Curvularia interseminata & ++ & ++ & ++ & ++ & ++ & ++ & ++ & + & - & - & ++ & ++ \\
\hline 8 & Cladosporium oxisporium & + & - & + & + & - & - & - & - & - & - & - & - \\
\hline 9 & Mycellia sterilia & ++ & - & ++ & - & ++ & - & - & - & + & - & - & - \\
\hline 10 & Nigrospora oryzae & - & - & - & + & + & - & - & - & - & - & + & - \\
\hline 11 & Penicillium spinulosum & ++ & ++ & ++ & ++ & + & + & ++ & + & - & - & ++ & ++ \\
\hline 12 & Penicillium sp. & + & - & + & + & + & - & - & - & - & - & - & + \\
\hline 13 & Rizopus nigricans & ++ & ++ & ++ & ++ & - & + & + & + & + & - & ++ & ++ \\
\hline 14 & Fusarium lactis & + & + & - & + & + & + & ++ & - & + & - & + & + \\
\hline 15 & undefined & ++ & ++ & ++ & + & ++ & + & ++ & + & - & - & ++ & ++ \\
\hline
\end{tabular}
- =0-30 CFU, $+=31-60 \mathrm{CFU},++=61-90 \mathrm{CFU},+++=91-120 \mathrm{CFU},++++=121-150 \mathrm{CFU}$ G1 = Malnicherra Tea Estate G2 = Lakkatura Tea Estate

On the other hand, from SDA petri plate count it was explored that maximum \% of contribution showed by Aspergillus fumigatus (12.05\%) followed by Curvularia interseminata (10.18\%), Aspergillus flavus (9.35\%), Aspergillus niger (8.88\%), Penicillium spinulosum (8.39\%), Cladosporium herbarum (8.22\%), Rhizopus nigricans $(7.77 \%)$, Mycelia sterilia (7.23\%), Fusarium lactis (5.19\%), Alternaria alternata (3.74\%), Penicillium sp. (3.49\%), Cladosporium oxysporum (2.95\%), Bispora sp. (2.70\%), Nigrospora oryzae (1.62\%). The \% of contribution of undefined bio particles in PDA and SDA were $7.72 \%$ and $8.22 \%$ respectively. In Lakkatura tea estate in PDA media a total 1935 colonies were identified and maximum \% of contribution showed by Cladosporium herbarum (11.57\%), followed by Aspergillus fumigatus (10.12\%), Rhizopus nigricans (9.87\%), Curvularia interseminata (9.66\%), Penicillium spinulosum (9.35\%), Aspergillus niger (8.94\%), Aspergillus flavus (8.83\%), Fusarium lactis (5.06\%), Alternaria alternata (4.34 \%), Penicillium sp. (3.73\%), Bispora sp. (3.15\%), Mycelia sterilia (2.73\%), Nigrospora oryzae (2.42\%), Cladosporium oxysporum $(2.42 \%)$ while in SDA media a total 1957 colonies were identified and the maximum \% of contribution showed by Cladosporium herbarum (11.13\%), followed by Curvularia interseminata (10.62\%), Aspergillus fumigatus (10.11\%), Rhizopus nigricans (9.60\%), Penicillium spinulosum (9.45\%), Aspergillus niger (9.09\%), Aspergillus flavus (9.09\%), Fusarium lactis (5.41\%), Alternaria alternata (4.64 \%), Bispora sp. (3.21\%), Penicillium sp. (3.01\%), Mycelia sterilia (2.70\%), Nigrospora oryzae (2.60\%), Cladosporium oxysporum (2.40\%). Besides, the \% of contribution of undefined bio particles in PDA and SDA were $7.70 \%$ and $6.84 \%$ respectively.

Table 2. Observation of total air borne fungal species and percentage of contribution in Malnicherra and Lakkatura Tea Estate

\begin{tabular}{|l|c|c|c|c|c|c|c|c|}
\hline \multirow{2}{*}{$\begin{array}{l}\text { Name of } \\
\text { fungal species }\end{array}$} & \multicolumn{3}{|c|}{ Malnicherra Tea Estate } & \multicolumn{3}{c|}{ Lakkatura Tea Estate } \\
\cline { 2 - 9 } & \multicolumn{2}{|c|}{ PDA media } & \multicolumn{2}{|c|}{ SDA media } & \multicolumn{2}{c|}{ PDA media } & \multicolumn{2}{c|}{ SDA media } \\
\cline { 2 - 9 } & $\begin{array}{c}\text { Total } \\
\text { colony }\end{array}$ & $\begin{array}{c}\text { \% of } \\
\text { contribution }\end{array}$ & $\begin{array}{c}\text { Total } \\
\text { colony }\end{array}$ & $\begin{array}{c}\text { \% of } \\
\text { contribution }\end{array}$ & $\begin{array}{c}\text { Total } \\
\text { colony }\end{array}$ & $\begin{array}{c}\text { \% of } \\
\text { contribution }\end{array}$ & $\begin{array}{c}\text { Total } \\
\text { colony }\end{array}$ & $\begin{array}{c}\text { of } \\
\text { contribution }\end{array}$ \\
\hline Alternaria alternata & 73 & 3.2 & 90 & 3.74 & 84 & 4.34 & 91 & 4.64 \\
\hline Aspergillus flavus & 240 & 10.53 & 225 & 9.35 & 171 & 8.83 & 178 & 9.09 \\
\hline Aspergillus fumigatus & 290 & 12.73 & 290 & 12.05 & 196 & 10.12 & 198 & 10.11 \\
\hline Aspergillus niger & 207 & 9.08 & 213 & 8.88 & 173 & 8.94 & 178 & 9.09 \\
\hline Bispora sp. & 47 & 2.06 & 65 & 2.7 & 61 & 3.15 & 63 & 3.21 \\
\hline Cladosporium herbarum & 186 & 8.16 & 198 & 8.22 & 224 & 11.57 & 218 & 11.13 \\
\hline Curvularia interseminata & 218 & 9.56 & 245 & 10.18 & 187 & 9.66 & 208 & 10.62 \\
\hline Cladosporium oxysporum & 69 & 3.02 & 71 & 2.95 & 47 & 2.42 & 47 & 2.4 \\
\hline Mycelia sterilia & 153 & 6.71 & 174 & 7.23 & 53 & 2.73 & 53 & 2.7 \\
\hline Nigrospora oryzae & 57 & 2.51 & 39 & 1.62 & 47 & 2.42 & 51 & 2.6 \\
\hline Penicillium spinulosum & 185 & 8.12 & 202 & 8.39 & 181 & 9.35 & 185 & 9.45 \\
\hline Penicillium sp. & 85 & 3.73 & 84 & 3.49 & 73 & 3.77 & 59 & 3.01 \\
\hline Rhizopus nigricans & 170 & 7.46 & 187 & 7.77 & 191 & 9.87 & 188 & 9.6 \\
\hline Fusarium lactis & 122 & 5.35 & 125 & 5.19 & 98 & 5.06 & 106 & 5.41 \\
\hline undefined & 176 & 7.72 & 198 & 8.22 & 149 & 7.7 & 134 & 6.84 \\
\hline
\end{tabular}

Here an interesting point to be considered that the abundance of fungal spore on the different culture media was varied. In both tea estates, the SDA media scored a higher number of spores than that of PDA media. Here the 14 types of fungal spores belonging in 10 genera were determined. During the investigation period, 16 fungal species of 12 genera were recorded in the air of tea garden of Darjeeling by Sharma [24]. 
Vol. 6, Issue 12, December 2019

The collective $\%$ contribution (Fig. 4) of the fungi on these two media revealed that at Malnicherra tea estate Aspergillus fumigatus (12.39\%) showed the maximum percentage followed by Aspergillus flavus (19.88\%), Curvularia interseminata (19.74\%), Aspergillus niger (17.96\%) whereas at Lakkatura tea estate Cladosporium herbarum $(22.70 \%)$ showed the maximum percentage followed by Curvularia interseminata (20.28\%), Aspergillus fumigatus (20.23\%), Rizopus nigricans (19.47\%). Hence Aspergillus, Curvularia, Cladosporium, Penicillium and Rhizopus were observed as the dominating genera in the air of tea estates. Earlier studying the air of Dhaka University campus Ahmed, Hossain [1] also found the abundance of Aspergillus Cladosporium, Curvularia Penicillium , Rhizopus, Alternaria, etc. This was mostly possible due to the similarity pattern of air composition of the country. Das and Bhattacharya [25] also found these species as the predominant fungal species in an agricultural farm of West Bengal.

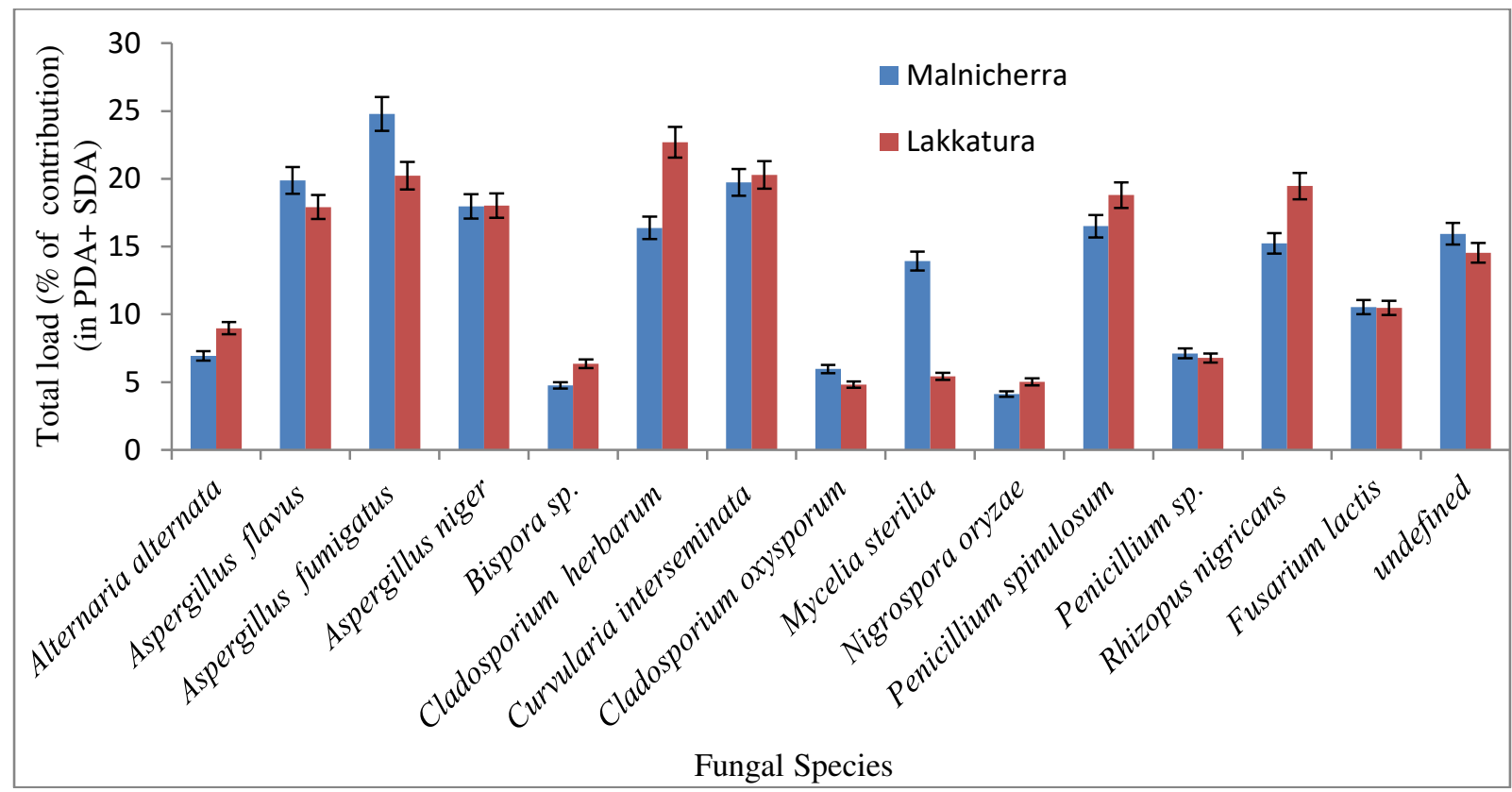

Fig. 4. Graphical representation of collective \% contribution of fungal colonies in Malnicherra and Lakkatura Tea Estate

Hence, it can be concluded that the air of tea gardens of Bangladesh are not free from aeromycoflora. In the present study, Aspergillus and Curvularia were observed as the most prominent genera in Malnicherra while Cladosporium, Aspergillus, and Rhizopus were prominent genera in Lakkhatura tea estate.

\subsection{Principal Component Analysis (PCA) in the total observation in Malnicherra \& Lakkhatura Tea Estate}

From the Principal Component Analysis for all species in Malnicherra \& Lakkhatura tea estate four most important species were observed i.e., Penicillium spinulosum (Loading 0.927), Aspergillus niger (Loading 0.922), Rizopus nigricans (Loading 0.915), Aspergillus fumigatus (Loading 0.900). This four species showed the highest variation as the Principal Component Analysis (Loading $\geq 0.80$ ).

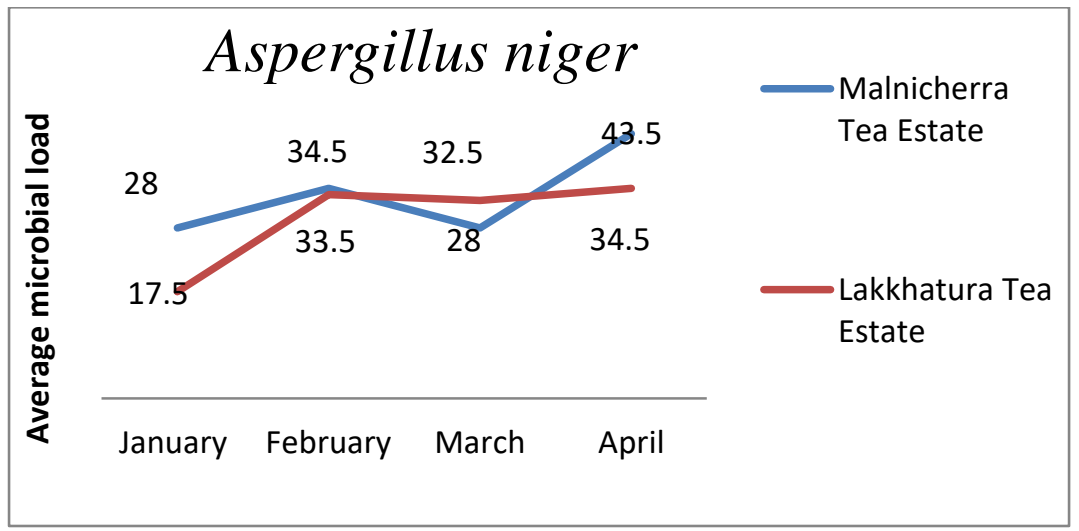

(a) 


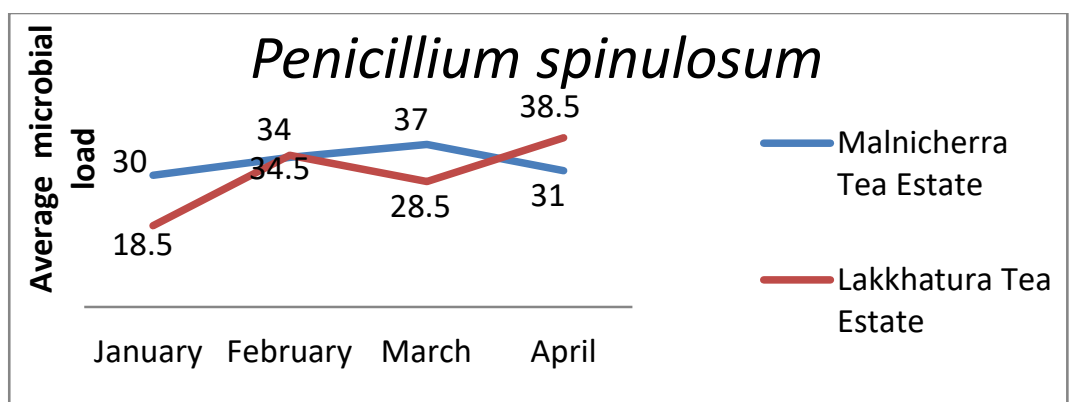

(b)

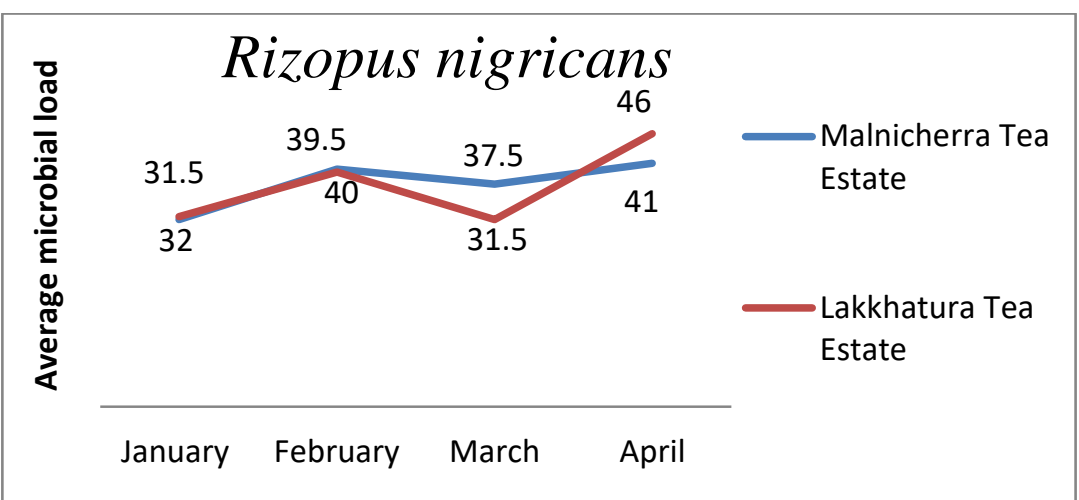

(c)

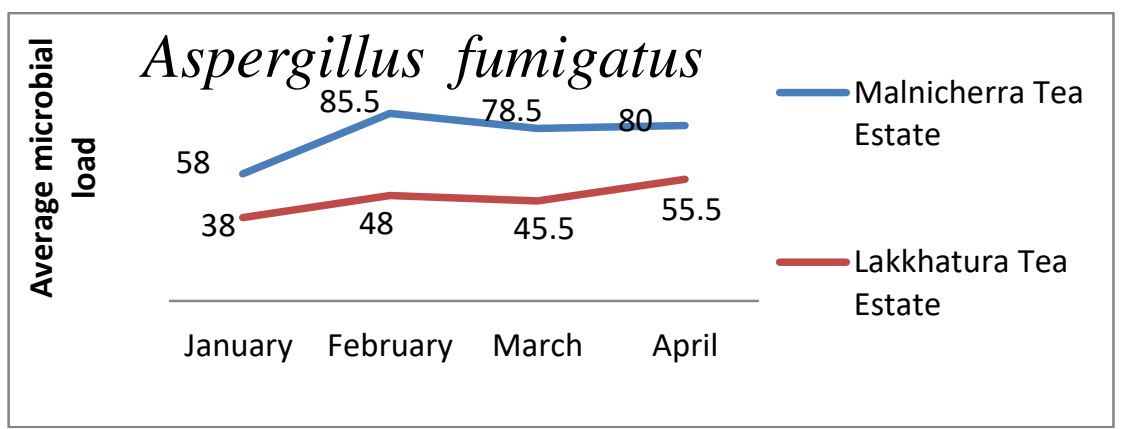

(d)

Fig. 5. Line graph showing average microbial load (in CFU) in throughout the duration of (a) Aspergillus niger; (b) Penicillium spinulosum; (c) Rizopus nigricans; (d) Aspergillus fumigatus

From the monthly abundance (Fig. 4) it was observed that in dry weather condition (January) the average microbial load (in CFU) in both the estate was at a minimum level. The reason might be the unfavorable condition with a very lower level of humidity. On the other hand at pre-monsoon and humid summer season the microbial count was comparatively higher than that of the winter season. In these periods the humidity and rainfall facilitate the growth and proliferation of air mycoflora largely. Verma [26] and Singh and Siddiqui [27] also observed similar fashion of microbial load and reported that this was attributed to favorable and unfavorable growth conditions. From the separate study Kulkarni [28] and Sawane [29] observed Aspergillus niger, Aspergillus fumigatus, Penicillium spinulosum and Cladosporium cladosporioides as the frequent fungal species in the rainy and summer season in public parks and different environments of India. It is evident that higher abundance of fungal spore is clearly dependent on daily rainfall. From a five year study on aeromycoflora Chakraborty, Gupta-Bhattacharya [30] stated that even a short shower can drastically change the concentration of the aeromycoflora. However, an exception observed for Aspergilluas fumigatus that its load was highest in dry winter (February) in Malnicherra tea estate. It was also noticeable that a periodic rise and fall with a significant numerical variation was observed between months in both the tea estate except for Penicillium spinulosum in Lakkatura tea estate. Similar types of rise and fall was observed by Rajan, Nigam [31] for atmospheric fungal flora at Kanpur. 


\section{International Advanced Research Journal in Science, Engineering and Technology}

Vol. 6, Issue 12, December 2019

\section{CONCLUSIONS}

From the above observations and results, it was concluded that the different zone had diversified aeromycoflora with a different number. The highest number of the microbial load was found in the field level (nursery and garden) and comparatively lowest load were found at the factory level. The microbial abundance and Principal Component Analysis (PCA) in both PDA and SDA media of both garden exhibited that Aspergillus fumigatus was the most dominating species. It was also observed that the fungal species showed seasonal fluctuations and supported by moderate temperature, air humidity, and rainfall and other meteorological parameters. As it is evident that the aeromycoflora cause harms to both plants and animals hence certain corrective measures, strict maintenance or precautions i.e., frequent cleaning and preventive processes should be taken to limit or overcome their incidence.

\section{REFERENCES}

[1]. Ahmed, J., K. Hossain, and M. Bashar, Aeromycoflora of the Dhaka University campus. Bangladesh Journal of Botany, 2013. 42(2): p. 273278.

[2]. Lanjewar, S., The Estimation of Moulds Air Pollution in Tilda, Raipur. Journal of Phytology, 2011.

[3]. Sabariego, S., C.D. De La Guardia, and F. Alba, The effect of meteorological factors on the daily variation of airborne fungal spores in Granada (southern Spain). International Journal of Biometeorology, 2000. 44(1): p. 1-5.

[4]. Kasprzyk, I., Aeromycology-main research fields of interest during the last 25 years. Ann Agric Environ Med, 2008. 15(1): p. 1-7.

[5]. Iannone R, Chernoff DI, Pringle A, Martin ST, Bertram AK. The ice nucleation ability of one of the most abundant types of fungal spores found in the atmosphere. Atmospheric Chemistry and Physics Discussions, 2010. 10(10): p. 24621-24650.

[6]. Ankush, K. and M. Bhajbhuje, Biodiversity of Aeromycoflora from Indoor Environment of Library. Int. Jour. Life Sci, 2014: p. 21-24.

[7]. Buzina, W., Aspergillus-classification and antifungal susceptibilities. Current pharmaceutical design, 2013. 19(20): p. 3615-3628.

[8]. Aimanianda V, Bayry J, Bozza S, Kniemeyer O, Perruccio K, Elluru SR, Clavaud C, Paris S, Brakhage AA, Kaveri SV, Romani L. Surface hydrophobin prevents immune recognition of airborne fungal spores (vol 460, pg 1117, 2009). Nature, 2010. 465(7300).

[9]. Nafis, A. and K. Sharma, Isolation of aeromycoflora in the indoor environment of chawri bazar metro-railway station, Delhi, India. Recent Research in Science and Technology, 2012. 4(3).

[10]. Ghosh D, Dhar P, Das AK, Uddin N. Identification and distribution of aeromycoflora in the indoor environment of Shyambazar Metro-Railway Station, Kolkata, India. African Journal of Microbiology Research, 2011. 5(31): p. 5569-5574.

[11]. Jadhay, S. and B. Lall, Seasonal variation of indoor aeromycoflora of Dr. Bhim Rao Ambedkar Hospital, Raipur. Advances in Plant Sciences, 2011. 24(1): p. 101-107.

[12]. Pathak, A.K., An extramural aero mycological investigation of dental college hospital associated environment. International Journal of Environmental Sciences, 2012. 2(4): p. 1952.

[13]. Manzelat, S.F., Aeromycoflora of Jizan, Saudi Arabia. EQA-International Journal of Environmental Quality, 2017. 26: p. 31-40.

[14]. Kurup VP, Banerjee B, Kelly KJ, Fink JN. Molecular biology and immunology of fungal allergens. Indian Journal of Clinical Biochemistry, 2000. 15(1): p. 31-42.

[15]. Elshafie, A.E., T. Al-Lawatia, and S. Al-Bahry, Fungi associated with black tea and tea quality in the Sultanate of Oman. Mycopathologia, 1999. 145(2): p. 89-93.

[16]. Khan, M. and S. Ali, An aerobiological study of the Dhaka city and its suburban areas. BANGLADESH JOURNAL OF BOTANY, 1984. 13(2): p. 214-219.

[17]. Pasha, M. and M.S. Hossain, Airborne bio-particulate objects at Chittagong University campus. Bangladesh Journal of Botany, 2011. 40(2): p. 189-191.

[18]. Hyde, H. and D. Williams, A census of mould spores in the atmosphere. Nature, 1949. 164(4172): p. 668.

[19]. Thirumala, S. and M. Nathu, Study of fungal spores diversity, in Malebenur region of Karnataka, India. International Journal of Current Microbiology and Applied Sciences, 2013. 2(3): p. 44-48.

[20]. Devi, J., S. Medhi, and T. Sarma, Aeromycological study of store houses of onion and ginger in Guwahati. J. of Life Sci, 2010.2 : p. 547-552.

[21]. Barnett, H.L. and B.B. Hunter, Illustrated genera of imperfect fungi. 1972.

[22]. Gulati A, Veni A, Sud RK, Shanker A, Tewary DK, Thakur M, Nadda G, Kumar A, Singh RD. Status and Prospects of Integrated Pest Management Strategies in Selected Crops: Tea. Integrated Pest Management: Applications, 2006. 18: p. 581-614.

[23]. Lanjewar, S. and K. Sharma, Intramural aeromycoflora of rice mill of Chhattisgarh. International Science Journal, 2014. 1(1): p. 40-45.

[24]. Sharma, K., Comparative study of aeromycoflora in relation to soil mycoflora of Darjeeling tea garden, India. Recent Research in Science and Technology, 2011.

[25]. Das, S. and S. Bhattacharya, Airborne culturable fungal flora of an agricultural farm in West Bengal and its relationship with meteorological factors. Ind J Aerobiol, 2007. 20: p. 1-8.

[26]. Verma, K., Fungi in the medical college of the Jabalpur city and the allergenic behavior of some species. Journal of the Indian Botanical Society, 1992. 71(1-4): p. 247-249.

[27]. Singh, A. and S. Siddiqui, A comparative aeromycological study of unpolluted and polluted air localities. J. Basic Appl. Mycol, 2009. 8(1\&2): p. 109-112.

[28]. Kulkarni, P., Aeromycological profile of the public parks of Bhilai Township, Chhattisgarh, India. Indian Journal of Science and Technology, 2011. 4(5): p. 558-560.

[29]. Sawane, A., A Survey of Airborne Penicillium in Different Environments of Nagpur. The Journal of Indian Botanical Society, 2010. 89(1 and2): p. $149-154$

[30]. Chakraborty, P., S. Gupta-Bhattacharya, and S. Chanda, Aeromycoflora of an agricultural farm in West Bengal, India: A five-year study (19941999). Grana, 2003. 42(4): p. 248-254

[31]. Rajan, B., S. Nigam, and R. Shukla. A study of the atmospheric fungal flora at Kanpur. in Proceedings of the Indian Academy of SciencesSection B. 1952. Springer. 